\title{
Planos municipais de saneamento básico: avaliação de 18 casos brasileiros*
}

\author{
Environmental sanitation municipal plans: an assessment of 18 Brazilian cases
}

Tatiana Santana Timóteo Pereira', Léo Heller²

口-

\begin{abstract}
RESUMO
A partir de 2007, os municípios brasileiros deparam-se com o novo desafio colocado pela Lei $n^{\circ} 11.445$, que trouxe uma nova organização para a gestão do setor de Saneamento Básico, assumindo-a não só como a prestação dos serviços mas também integrando-a ao planejamento, à regulação, à fiscalização e ao controle social. Neste trabalho, visando compreender dificuldades e potencialidades para o planejamento, foram avaliados 18 planos municipais de saneamento básico em uma amostragem que inclui as 5 macrorregiões do país e 14 estados. A avaliação foi norteada pelos princípios da universalidade, equidade, integralidade, intersetorialidade e qualidade; pela instituição da política; pela capacidade de gestão; e pela sustentabilidade. Na maioria dos casos, constatou-se fragilidade na instituição da política e que a incorporação dos princípios nos planos ocorreu de forma incipiente, embora alguns deles tenham se destacado pela maior aderência aos princípios avaliados (Alagoinhas, BA; Morada Nova, CE; Ariquemes, RO, e Ouro Branco, MG).
\end{abstract}

Palavras-chave: saneamento básico; planejamento; participação social; plano municipal.

\begin{abstract}
Since 2007, Brazilian municipalities have faced the new challenge posed by Law 11,445, which brought a new organization to the sector management, assuming it as not only services provision but also planning, regulation, supervision and social control. In this paper, 18 environmental sanitation municipal plans were assessed, aiming at understanding difficulties and potentialities for the planning process. Five geographical regions of the country and 14 states were included in the sample. The assessment was guided by the principles of universality, equity, integrality, cross-sectoral relations, quality, policy implementation, management capacity and sustainability. In most cases, weaknesses in policy implementation were identified, as well as the incorporation of the principles in the plans took place only incidentally, although some of them have stood out due to greater adherence to the principles considered (Alagoinhas, BA; Morada Nova, CE; Ariquemes, RO, e Ouro Branco, MG).
\end{abstract}

Keywords: environmental sanitation; planning; social participation; environmental sanitation municipal plan.

\section{INTRODUÇÃO}

A Lei $n^{\circ} 11.445$ (BRASIL, 2007) foi aprovada depois de quase duas décadas marcadas pela ausência de regulamentação e ordenamento jurídico, e estabeleceu as diretrizes nacionais para o saneamento básico, que passa a ser compreendido como o conjunto das ações de abastecimento de água (AA), esgotamento sanitário (ES), manejo dos resíduos sólidos (MRS) e manejo das águas pluviais (MAP). A Lei também definiu novas atribuições para os municípios, como titulares dos serviços, entre elas a implantação da política e a elaboração do
Plano Municipal de Saneamento Básico (PMSB). A gestão dos serviços passa a englobar o conjunto das atividades de planejamento, prestação dos serviços, regulação e fiscalização, todas elas acompanhadas e submetidas à participação e ao controle social. Além disso, o saneamento passa a ser orientado pelos princípios da universalização, integralidade, intersetorialidade, adoção de tecnologias apropriadas, consideração das peculiaridades locais e regionais, eficiência e sustentabilidade econômica, transparência, segurança, qualidade e regularidade (BRASIL, 2007).

\footnotetext{
口

*Baseado na monografia "Conteúdo e metodologia dos planos municipais de saneamento básico: um olhar para 18 casos no Brasil", apresentada pela primeira autora ao Curso de Especialização em Gestão e Tecnologia do Saneamento da Escola Nacional de Saúde Pública, como requisito parcial à conclusão do curso, e orientada pelo segundo autor. 'Mestranda em Gestão e Regulação dos Serviços Públicos de Saneamento Básico pela Escola Nacional de Saúde Pública da Fundação Oswaldo Cruz (ENSP/Fiocruz). Especialista em Gestão e Tecnologia do Saneamento. Analista de Infraestrutura em Saneamento do Ministério das Cidades - Brasília (DF), Brasil.

2Doutor em Epidemiologia. Pesquisador do Centro de Pesquisas René Rachou/Fiocruz - Belo Horizonte (MG), Brasil. Relator Especial do Direito Humano à Água e ao Esgotamento Sanitário, das Nações Unidas.

Endereço para correspondência: Tatiana Santana Timóteo Pereira - SHCES Quadra 1311, Bloco F, apto. 409 - $70658-316$ - Cruzeiro Novo - Brasília (DF), Brasil - E-mail: tatianastp@yahoo.com.br Recebido: 07/08/12 - Aceito: 01/12/14 - Reg. ABES: 98824
} 
O PMSB consiste em um dos principais instrumentos da política municipal, além de ser uma condição para a validade dos contratos de prestação dos serviços e um requisito para o acesso a recursos federais a partir de 2014 (BRASIL, 2007; BRASIL, 2010a). Em função disso, os municípios têm iniciado a implementação da Lei por meio da elaboração do plano, entretanto em muitos casos sem incorporar os princípios, $\mathrm{o}$ conteúdo mínimo e o processo participativo requeridos (SILVA, 2012).

Por outro lado, percebe-se que parte dos planos também não emprega metodologias adequadas de planejamento ou adota métodos não condizentes com os princípios da Lei ${ }^{\circ} 11.445$ (SILVEIRA, 2012; SILVEIRA et al., 2013a; SILVEIRA et al., 2013b). Entre as escolas de planejamento que vêm sendo recomendadas para orientar a avaliação, destacam-se o Planejamento Normativo, o Planejamento Estratégico Situacional (PES) e a Prospectiva Estratégica (BRASIL, 2014; SILVEIRA, 2012).

O Planejamento Normativo, disseminado na América Latina pela Comissão Econômica para a América Latina e o Caribe (CEPAL), e muito adotado no Brasil, é um método originário de teorias tecnicistas, positivistas e economicistas, marcado pela ausência de diálogo entre o técnico e o político, e pela sobrevalorização de aspectos econômicos em detrimento de dimensões como a política e a social. Considera principalmente a visão de quem planeja, ignorando a existência de cooperação e conflitos, e de outros atores no "jogo social". Não considera a incerteza, adota uma verdade absoluta para o futuro, que ocorrerá de forma linear e homogênea, o que pressupõe a adoção de projeções puramente estatísticas e matemáticas (HUERTAS, 1996; MATUS, 1984; MATUS, 1989).

Já o PES consiste em uma metodologia que considera diversas dimensões políticas, técnicas, sociais, entre outras, buscando incorporar as visões de atores envolvidos no processo social, como governo e sociedade civil, e tem como princípio que quem governa é quem planeja. É composto por quatro momentos: explicativo, normativo, estratégico e tático-operacional, que podem ocorrer concomitantemente, resultando na permanente interação e somando dinamismo ao processo:

1. No momento explicativo, procura-se explicar a realidade, como surge e progride o problema. Adota o conceito de análise situacional, em contraponto ao de diagnóstico, por considerar que para cada ator a leitura da realidade conterá elementos intrínsecos à sua experiência, e que o plano deve levar em consideração não só os aspectos técnicos, econômicos e operacionais mas também os sociais, culturais, políticos e institucionais.

2. No momento normativo, elabora-se o plano, e para cada problema são definidas as ações necessárias para enfrentar as causas, alcançar os objetivos e chegar até a situação desejada, levando-se em conta as incertezas e os cenários. Para lidar com emergências e contingências, como contaminação acidental de mananciais, enchentes e inundações, são elaborados planos de contingência.

3. No momento estratégico, constrói-se a viabilidade política, técnica e social do plano, considerando os atores, seus interesses, motivações e influências; as táticas e estratégias a serem adotadas para lidar com eles; a trajetória a ser adotada e as operações a serem realizadas.

4. O momento tático-operacional é quando o planejamento é implementado, monitorado e revisado pelo ator responsável pelo planejamento, que pode ser um governo, uma entidade, entre outros. O PES pressupõe esforços para o cumprimento do planejamento, para que as decisões não recaiam no improviso, já que as urgências, a velocidade da ação, a desinformação, a deficiência executora e a incapacidade de recalcular o plano tendem a predominar no cotidiano. Nesse momento, é importante detectar os atores que se esforçam para que predomine o plano e os que desejam atuar por improvisação (AZEVEDO, 1992; HUERTAS, 1996; MATUS, 1989; MATUS, 2006; RIVERA, 1992).

O planejamento baseado em cenários, também conhecido por Prospectiva Estratégica, vem se consolidando como a principal técnica de prospecção e normalmente contempla as etapas:

1. formulação e análise do problema, delimitando o sistema no qual o objeto a ser planejado está inserido, geralmente de forma participativa;

2. diagnóstico do sistema, contemplando a organização e o ambiente, os processos, as árvores de competência e a análise estratégica;

3. identificação e hierarquização das variáveis que exercem maior influência na evolução do sistema;

4. identificação da dinâmica da organização, seu ambiente, desenvolvimento, estratégias dos atores e arenas;

5. redução de incertezas por meio da consulta a especialistas, para identificar tendências e detalhar cenários mais prováveis;

6. destaque dos projetos mais coerentes e opções estratégicas compatíveis com a identidade da organização e com o cenário mais provável;

7. avaliação das opções estratégicas;

8. escolhas estratégicas e hierarquização de objetivos envolvendo uma instância colegiada;

9. definição de metas, pactuação de objetivos, definição de um sistema de monitoramento idealmente externo à organização (BUARQUE, 2003; GODET, 2006).

Além dessas metodologias e técnicas, podem-se mencionar o Foresight, o Quadro Lógico, o Planejamento de Projeto Orientado por Objetivos (ZOPP), entre outras. A escolha por um método deve se pautar pelos seus princípios, os quais devem ser condizentes com o objeto planejado.

O Plano Nacional de Saneamento Básico (Plansab) foi elaborado considerando princípios e métodos de algumas das escolas de planejamento, em especial do PES e da Prospectiva Estratégica (BRASIL, 2014). Trata-se de metodologias selecionadas para realizar o planejamento determinado pela Lei do Saneamento, por serem métodos que apresentam como princípios a visão dos diversos atores que atuam no setor, como poder público, sociedade civil organizada, prestadores de serviços, trabalhadores, movimento popular, entre outros, o que se consolida mediante a participação social. 
Portanto, são estratégias para se planejar, que podem ser utilizadas para a elaboração dos PMSB.

Em vista desse quadro, este trabalho objetivou avaliar os PMSB e, a partir daí, apontar o que pode ser aprimorado na elaboração e no conteúdo dos planos para que a implementação do planejamento possa de fato contribuir para a melhoria das condições de saneamento básico e de qualidade de vida da população.

\section{PERCURSO METODOLÓGICO}

Por meio de busca em sítios eletrônicos, foram identificados diversos PMSB e selecionados 18 municípios, priorizando-se aqueles que contemplaram os 4 componentes do saneamento básico, considerando as 5 macrorregiões do país, o maior número possível de estados: 14. Além disso, buscou-se compor um conjunto de experiências com condições diferentes de cobertura dos serviços de saneamento básico. Os municípios selecionados encontram-se no Quadro 1.

Foram selecionados municípios de portes populacionais diversificados e diferentes níveis de cobertura de saneamento básico, sendo Caseiros o menor em número de habitantes, e São Paulo o maior. Sete dos municípios são integrantes de regiões metropolitanas: Belo Horizonte, Parnamirim, Rio de Janeiro, Salvador, São Paulo, Senador Canedo e Serra, e seis deles contêm em seus territórios aglomerados subnormais ${ }^{1}$ : Belo Horizonte, Blumenau, Boa Vista, Rio de Janeiro, Salvador, São Paulo e Serra, sendo Salvador a cidade com maior contingente populacional nessas áreas, com 33\% dos habitantes. O município com maior percentual da população em áreas rurais é Caseiros, com $51 \%$ dos habitantes, enquanto Belo Horizonte, Bombinhas, Parnamirim e Rio de Janeiro, de acordo com o Censo 2010, reúnem100\% de seus habitantes em áreas urbanas, apesar de alguns desses considerarem a existência de áreas rurais (IBGE, 2010).

O Censo 2010 também apontou que todos esses municípios apresentam déficits de cobertura para os serviços de saneamento básico, alguns em menor e outros em maior proporção. Belo Horizonte possui a maior cobertura por rede geral de distribuição de água, com 99,7\%, enquanto Ariquemes possui a menor cobertura, com $35 \%$. Também da capital mineira é a maior cobertura por rede geral de esgoto ou pluvial, com $96 \%$, enquanto a menor cobertura está em Caseiros com 0,6\%. Para a coleta de resíduos por serviço de limpeza urbana, Blumenau apresenta a maior cobertura com $98 \%$, enquanto Morada Nova, apenas $49 \%$ dos domicílios atendidos (IBGE, 2010).

Os planos selecionados foram elaborados de diversas formas por equipe própria, em parceria com universidades, mediante a

'É o conjunto constituído por 51 ou mais unidades habitacionais caracterizadas por ausência de título de propriedade e pelo menos uma das características abaixo: irregularidade das vias de circulação e do tamanho e forma dos lotes; e/ou carência de serviços públicos essenciais (como coleta de lixo, rede de esgoto, rede de água, energia elétrica e iluminação pública) (IBGE, 2010) contratação de consultoria, e até mesmo pelo prestador de serviços - e três deles contaram com recursos de órgãos federais Fundação Nacional da Saúde (FUNASA), Ministério das Cidades (MCIDADES) e Petrobras. O primeiro elaborado foi o de Belo Horizonte em 2001, anterior à Lei do Saneamento, e o último concluído foi o da Serra, em 2012.

Para analisar os planos, foram definidas categorias, sendo cinco delas relacionadas aos princípios da lei:

1. universalidade,

2. equidade,

3. integralidade,

4. intersetorialidade, $\mathrm{e}$

5. qualidade,

e três relacionadas à:

1. política municipal de saneamento básico,

2. capacidade de gestão,

3. sustentabilidade social e governança.

Para analisar cada categoria foram criadas subcategorias que demonstram o que foi considerado em cada princípio para avaliar os planos municipais, conforme Quadro 2.

Uma das subcategorias da política municipal foi o conteúdo mínimo do plano, para o qual foi elaborado um checklist contendo todos os dispositivos relacionados ao PMSB da Lei do Saneamento e de seu Decreto de Regulamentação.

Para avaliar cada subcategoria, foram definidas palavras-chave para as quais foram feitas buscas nos documentos dos planos e, a partir da localização dos termos, procedeu-se à análise de conteúdo para identificar a relação com as categorias. A descrição das subcategorias adotadas e investigadas em cada categoria será apresentada na seção a seguir, "Resultados e Discussão".

\begin{tabular}{|c|c|c|c|c|c|c|c|}
\hline Região & UF & Município & $\begin{array}{c}\text { População } \\
\text { (hab.) }\end{array}$ & Região & UF & Município & $\begin{array}{l}\text { População } \\
\text { (hab.) }\end{array}$ \\
\hline \multirow{2}{*}{$\mathrm{CO}$} & GO & $\begin{array}{l}\text { Senador } \\
\text { Canedo }\end{array}$ & 84.443 & \multirow{3}{*}{ S } & RS & Caseiros & 3.007 \\
\hline & MT & $\begin{array}{c}\text { Tangará da } \\
\text { Serra }\end{array}$ & 83.431 & & \multirow[t]{2}{*}{ SC } & Blumenau & 309.011 \\
\hline \multirow{2}{*}{$\mathrm{N}$} & $\mathrm{RO}$ & Ariquemes & 90.353 & & & Bombinhas & 14.293 \\
\hline & RR & Boa Vista & 284.313 & \multirow{6}{*}{ SE } & ES & Serra & 409.267 \\
\hline \multirow{4}{*}{ NE } & \multirow[t]{2}{*}{ BA } & Alagoinhas & 141.949 & & \multirow{3}{*}{ MG } & $\begin{array}{c}\text { Belo } \\
\text { Horizonte }\end{array}$ & 2.375 .151 \\
\hline & & Salvador & 2.675 .656 & & & Buritis & 22.737 \\
\hline & CE & $\begin{array}{c}\text { Morada } \\
\text { Nova }\end{array}$ & 62.065 & & & $\begin{array}{c}\text { Ouro } \\
\text { Branco }\end{array}$ & 35.268 \\
\hline & RN & Parnamirim & 202.456 & & RJ & $\begin{array}{l}\text { Rio de } \\
\text { Janeiro }\end{array}$ & 6.320 .446 \\
\hline $\mathrm{S}$ & PR & Toledo & 119.313 & & $\mathrm{SP}$ & São Paulo & 11.253 .503 \\
\hline
\end{tabular}

Fonte: IBGE, 2010. 


\section{RESULTADOS E DISCUSSÃO}

Os planos selecionados foram avaliados a partir das referências conceituais sobre o planejamento apresentadas na introdução e dos princípios da política pública de saneamento básico, conforme metodologia descrita anteriormente e resultados apresentados a seguir.

\section{Universalidade}

O princípio da universalidade pressupõe que o saneamento é um direito e que, portanto, todos os brasileiros e todas as brasileiras devem ter acesso aos serviços, sem qualquer distinção de classe, gênero, cor

Quadro 2 - Categorias e subcategorias de análise.

\begin{tabular}{|c|c|}
\hline Categorias & Subcategorias \\
\hline Universalidade & $\begin{array}{l}\text { Princípio ou objetivo; soluções individuais; } \\
\text { apropriação das soluções ou serviços; } \\
\text { características sociais da população sem acesso; } \\
\text { metas para a universalização; instrumentos e } \\
\text { investimentos para a universalização. }\end{array}$ \\
\hline Equidade & $\begin{array}{l}\text { Princípio ou objetivo; consideração das ocupações } \\
\text { irregulares e comunidades especiais; áreas rurais; } \\
\text { características sociais da população consideradas } \\
\text { na definição de metas; características sociais para a } \\
\text { priorização de investimentos; ações voltadas para a } \\
\text { população carente; identificação dos usuários de baixa } \\
\text { renda e apontamento de solução para o acesso aos } \\
\text { serviços; tarifa social e/ou subsídios; critérios para a } \\
\text { interrupção no abastecimento de água. }\end{array}$ \\
\hline Integralidade & $\begin{array}{l}\text { Quatro componentes do saneamento básico; plano } \\
\text { municipal de gestão integrada de resíduos sólidos; } \\
\text { controle de vetores. }\end{array}$ \\
\hline Intersetorialidade & $\begin{array}{l}\text { Política urbana e plano diretor; habitação; combate } \\
\text { à pobreza e sua erradicação; recursos hídricos e } \\
\text { planos de bacias; política e plano de prevenção } \\
\text { de riscos e desastres; política de saúde; proteção } \\
\text { do meio ambiente; promoção da igualdade racial; } \\
\text { política de gênero. }\end{array}$ \\
\hline $\begin{array}{l}\text { Qualidade dos } \\
\text { serviços públicos }\end{array}$ & $\begin{array}{l}\text { Qualidade da água; tratamento do esgoto; } \\
\text { tratamento e disposição final de resíduos sólidos; } \\
\text { controle de inundações; cortesia no atendimento } \\
\text { ao usuário; regularidade/continuidade; condições } \\
\text { técnicas e operacionais e de manutenção. }\end{array}$ \\
\hline $\begin{array}{l}\text { Política municipal } \\
\text { de saneamento } \\
\text { básico }\end{array}$ & $\begin{array}{l}\text { Conteúdo mínimo do plano; prestação de serviços; } \\
\text { regulação e fiscalização; garantia do atendimento } \\
\text { essencial à saúde pública e volume mínimo per } \\
\text { capita; direitos e deveres dos usuários; controle } \\
\text { social; sistema de informações; intervenção e } \\
\text { retomada do fundo municipal de saneamento; } \\
\text { instrumento de aprovação da política. }\end{array}$ \\
\hline $\begin{array}{l}\text { Capacidade de } \\
\text { gestão }\end{array}$ & $\begin{array}{l}\text { Metodologia de planejamento; análise política e } \\
\text { institucional no plano; existência e vigência de } \\
\text { contrato de prestação de serviços (não se aplica } \\
\text { para autarquias); condições de validade dos } \\
\text { contratos; SNIS; coordenação do processo de } \\
\text { elaboração do plano; mecanismos de avaliação e } \\
\text { monitoramento; indicadores para avaliar a eficiência; } \\
\text { indicadores para avaliar a eficácia. }\end{array}$ \\
\hline $\begin{array}{l}\text { Sustentabilidade } \\
\text { social e de } \\
\text { governança }\end{array}$ & $\begin{array}{l}\text { Ampla divulgação; identificação dos atores } \\
\text { envolvidos; aprovação do plano e da política por } \\
\text { órgão(s) colegiado(s) de controle social; intensidade } \\
\text { de participação; previsão de participação na } \\
\text { implementação; instrumento de aprovação do plano. }\end{array}$ \\
\hline
\end{tabular}

da pele e outras (BRASIL, 2014; PAIM, 2011). Apesar de todos os 18 planos apontarem a universalização dos serviços como princípio ou objetivo, apenas a metade deles considerou as soluções individuais que são adotadas pela população que não tem acesso aos serviços; apenas 4 avaliaram a apropriação das soluções ou serviços e identificaram as características sociais da população sem acesso; somente 6 definiram metas para a universalização dos serviços contemplando toda a população; e 3 apontaram instrumentos, por exemplo, um Fundo Municipal, e os investimentos necessários para a universalização. Os que atenderam ao maior número de subcategorias, 5 das 6 , foram os planos de Ariquemes e Ouro Branco, e os que atenderam a apenas 1 foram os de Senador Canedo, Boa Vista, Serra, Buritis e Blumenau.

Diversas soluções foram apresentadas pelos planos, como alternativas adotadas pela população que não tem acesso ao serviço de $\mathrm{AA}$, por exemplo, poço, açude, chafariz, cisterna, carro-pipa, nascente, água envasada e até mesmo algumas técnicas para o tratamento domiciliar, como filtração, fervura e cloração. Para o ES, foram mencionadas soluções como fossa rudimentar, fossa séptica, sumidouro, infiltração, lançamento in natura, lançamento na rede de drenagem. Para o MRS, foi mencionada a queima, o uso de caçambas estacionárias, a coleta por meio de carrinho de mão e "lixão". Na maioria dos casos, não foi avaliada a qualidade e a adequação da solução.

O plano de Boa Vista apresentou proposta de execução de instalações hidrossanitárias e de caixas de água, inclusive considerando a limpeza dessas como serviço público a ser feito a cada seis meses. Belo Horizonte considera que o poder público deve contribuir para a conexão dos domicílios aos sistemas públicos, inclusive por meio de subsídios aos usuários de baixa renda.

\section{Equidade}

A equidade é um princípio definido pela "superação de diferenças evitáveis, desnecessárias e injustas", que possibilita destacar uma população em situação de maior vulnerabilidade para que esta seja alvo prioritário das intervenções (BRASIL, 2014; PAIM, 2011). Embora não seja um princípio explícito, está implícito na Lei do Saneamento em diversos dispositivos voltados para a população de baixa renda, habitantes de áreas rurais, indígenas, remanescentes de quilombo, comunidades especiais e catadores de materiais recicláveis. Foram 6, dos 18 planos, os que declararam de forma explícita a equidade como um princípio ou um objetivo do plano. Também foram 4 desses os que consideraram o maior número de subcategorias avaliadas: Ouro Branco atendeu a 5 das 8; Alagoinhas, Morada Nova e Ariquemes atenderam a 4. Os que atenderam a um número menor foram Tangará da Serra com nenhuma atendida, seguido de Senador Canedo, Parnamirim, Buritis, Toledo, Caseiros e Blumenau que atenderam plenamente ou parcialmente a apenas 1 subcategoria. Oito municípios consideraram as ocupações irregulares e comunidades especiais existentes em seus territórios; também foram 8 os que consideraram as áreas 
rurais; nenhum plano definiu metas a partir das características sociais da população; 3 municípios fizeram a priorização de investimentos considerando-se as características sociais; 7 planos definiram ações voltadas para a população carente; 2 planos identificaram a população de baixa renda e apontaram solução para o seu acesso; 8 planos analisaram e/ou instituíram tarifa social e/ou subsídio; e somente o município de Boa Vista abordou a definição de critérios para a interrupção do AA que garantam a preservação das condições mínimas de manutenção da saúde.

O plano de Alagoinhas contou com a participação da União das Associações Rurais de Alagoinhas e apresentou como meta ampliar o quadro e promover a capacitação e formação de recursos humanos, capazes de atuar nas áreas urbanas e rurais do município, além de ter realizado diversas reuniões em cada uma das comunidades rurais. Esse plano é o único que fez uma análise crítica da estrutura tarifária aplicada pelo prestador de serviços de água e esgoto e constatou que, para as tarifas residenciais, normal e social, existe uma proximidade relativa dos valores aplicados em todas as faixas de consumo acima de $10 \mathrm{~m}^{3}$, apesar da diferença de cerca de $40 \%$ na tarifa básica. Propõe, como forma de propiciar a inclusão social de usuários de baixa renda e de inibir ligações clandestinas, a instituição de uma tarifa social "popular" no valor simbólico de $\mathrm{R} \$ 1,00$, podendo ser em caráter temporário e com número fixo de beneficiários. Para garantir a sustentabilidade financeira, os valores seriam compensados por outros usuários. Outros planos abordaram a tarifa social, entretanto sem avaliar criticamente a estrutura tarifária.

O plano de Ouro Branco definiu como meta universalizar e garantir a qualidade da água de abastecimento e dos padrões de efluentes de esgotos domésticos para comunidades rurais, depois de identificar diversos problemas no diagnóstico, o qual contou com pesquisa realizada por equipe do Programa de Saúde da Família (PSF), que visitou cerca de 45\% dos domicílios da área rural. Tal fato merece destaque uma vez que muitos planos desconsideram as áreas rurais e mesmo quando as consideram o fazem de forma incipiente.

\section{Integralidade}

A integralidade visa propiciar um ambiente com salubridade ambiental, o que só é possível quando se considera o conjunto das intervenções sanitárias englobando os quatro componentes do saneamento à determinada localidade (BRASIL, 2014; PAIM, 2011). Dos 18 planos avaliados, 10 contemplaram o conjunto dos 4 componentes do saneamento básico, conforme a Lei do Saneamento: Alagoinhas, Morada Nova, Parnamirim, Ariquemes, Boa Vista, Belo Horizonte, Ouro Branco, Caseiros, Blumenau e Bombinhas. Os outros 8 contemplaram apenas os componentes AA e ES. Com relação ao Plano Municipal de Gestão Integrada de Resíduos Sólidos, exigência da Lei $n^{\circ} 12.305$, que institui a Política Nacional de Resíduos Sólidos (BRASIL, 2010b), sendo permitida a inserção do seu conteúdo no PMSB, foram identificados alguns de seus elementos em 4 planos: Alagoinhas, Morada Nova, Ariquemes e Ouro Branco. Deve ser lembrado que os 18 municípios estudados, para se adequarem à legislação, deverão elaborar o plano de resíduos, contemplando, além dos resíduos sólidos domiciliares, de serviços de saúde e de construção civil, outros tipos de resíduos, como os industriais, de mineração, pilhas e baterias, embalagens de agrotóxicos, agrossilvopastoris, de serviços de transporte, pneus, eletrônicos, entre outros. Foram 3 os planos que contemplaram de forma mais detalhada o controle de vetores: Belo Horizonte, São Paulo e Blumenau.

\section{Intersetorialidade}

Os problemas que devem ser enfrentados por um governo são sempre marcados por suas naturezas transversais, já que perpassam horizontalmente diversas especialidades; por isso, cada vez mais, é necessário formar profissionais e gestores com a visão multidisciplinar das cidades, para perseguir a articulação das diversas políticas públicas (MATUS, 2007). De uma forma geral, foi constatado que os planos avaliados são tímidos na abordagem da articulação com outras políticas associadas ao saneamento básico, o que foi observado para o princípio da intersetorialidade. Nenhum dos planos observou de forma satisfatória os elementos da política de desenvolvimento urbano, do plano diretor e da política habitacional. Muitos deles fazem referências ao plano diretor, mas nenhum trouxe para o PMSB todos os elementos relevantes, como os parâmetros de uso e ocupação do solo; a definição do perímetro urbano da sede e dos distritos dos municípios, das Zonas Especiais de Interesse Social (ZEIS), do zoneamento de áreas de parcelamento e edificação compulsórios, das áreas para habitação de interesse social e por meio do mercado imobiliário; a identificação de ocupações irregulares em áreas de preservação permanente (APP), da situação fundiária, dos eixos de desenvolvimento da cidade e de projetos de parcelamento e/ou urbanização (BORJA, 2011). Um deles, o plano de Blumenau, nem sequer mencionou o plano diretor.

Para a política de habitação, foi observado se os planos abordaram: o quadro da oferta habitacional; as condições de acesso às modalidades de intervenção e financiamento habitacional; a disponibilidade do solo urbanizado para a população de baixa renda; a demanda habitacional; e a análise das projeções do déficit habitacional (BORJA, 2011). Foram quatro os planos que não fizeram qualquer referência à política de habitação: Senador Canedo, Buritis, Toledo e Blumenau.

Sobre a situação ambiental e dos recursos hídricos, os planos deveriam conter: uma caracterização geral e delimitação das bacias hidrografias; caracterização dos ecossistemas naturais; situação e perspectivas dos usos e da oferta de água em bacias potenciais e o lançamento de resíduos líquidos e sólidos; condições da gestão dos recursos hídricos como existência de plano, de comitê, entre outros. Da área da saúde, prevê-se que o plano aborde: a ocorrência de morbidades relacionadas à ausência de saneamento; estado nutricional e ocorrência de diarreia aguda em crianças de até quatro anos; atuação do PSF; programas de educação sanitária, ambiental e de assistência social (BORJA, 2011).

Com relação às políticas de recursos hídricos e planos de bacia, de saúde, de proteção do meio ambiente e da promoção da igualdade racial, nenhum 
dos planos atendeu de forma satisfatória à abordagem desses setores, trazendo os aspectos de relevância para o saneamento. A abordagem mais incipiente foi a referente à política de promoção da igualdade racial, considerada de forma parcial pelo plano de Salvador. A política de combate à pobreza e sua erradicação também foi pouco abordada pelos planos, de forma parcial por apenas cinco municípios e de forma mais abrangente pelo município de Bombinhas. Apenas o plano de Senador Canedo não abordou aspectos da política de saúde e todos os demais a abordaram de forma incipiente. Isso também foi observado para a política ambiental, sendo Buritis o que nada considerou a seu respeito. Já para a perspectiva de gênero, um dos planos abordou de forma mais incisiva, o de Alagoinhas, quatro a incorporaram de forma parcial, e os demais não fizeram qualquer menção.

De uma forma geral, não foi possível destacar planos que contemplaram um número maior de subcategorias da integralidade, mas os que não atenderam a pelo menos cinco foram os de Senador Canedo, Buritis, Toledo e Blumenau.

\section{Qualidade dos serviços públicos}

Foram dois os planos que contemplaram de forma satisfatória a qualidade para os quatros componentes do saneamento: Alagoinhas e Parnamirim. Outros três abordaram a qualidade de forma satisfatória para três componentes: Morada Nova, Ariquemes, Ouro Branco e Bombinhas. Os planos de Senador Canedo, Tangará da Serra, Serra, Buritis, Rio de Janeiro, São Paulo, Toledo e Caseiros abordaram em apenas um.

Apenas seis municípios apresentaram e discutiram em seus planos os resultados de análises da qualidade da água para verificar o atendimento aos padrões da Portaria $n^{\circ} 518$, vigente quando os planos foram elaborados, atualizada em 2011 pela Portaria $n^{\circ} 2.914$. Foram eles: Alagoinhas, Morada Nova, Parnamirim, Ariquemes, Ouro Branco e Bombinhas. A maioria dos planos abordou a qualidade da água de forma incipiente, sem apresentar dados de análises laboratoriais, ou apresentou índices calculados pelos prestadores de serviços, que acabam camuflando quais são, de fato, os problemas operacionais e os problemas da qualidade da água decorrentes deles. Em dois planos a qualidade da água distribuída à população não foi abordada de forma alguma: Belo Horizonte e Blumenau. Sobre a continuidade e a regularidade dos serviços, dez planos avaliaram a ocorrência de intermitência, e outros cinco não fizeram qualquer referência ao assunto: Belo Horizonte, Buritis, Rio de Janeiro, Toledo e Caseiros.

Com relação ao tratamento dos efluentes, apenas quatro municípios apresentaram dados da análise da qualidade da água no corpo receptor: Tangará da Serra, Alagoinhas, Salvador e Parnamirim. Esses planos apresentaram dados para pelo menos três dos seguintes parâmetros: DBO, DQO, OD, nitrogênio, fósforo, sólidos em suspensão ou totais, $\mathrm{pH}$, temperatura e turbidez.

Com exceção do município de Caseiros, que abordou o tema de forma parcial, todos os outros que contemplaram o componente MRS em seus planos abordaram a coleta seletiva, o manejo dos resíduos de serviços de saúde e de resíduos da construção civil, e a adequada destinação final dos resíduos.
Os planos que contemplaram o MAP pautaram a sua abordagem pelo controle de inundações por meio de técnicas que promovam a sustentabilidade ambiental e a minimização de intervenções físicas. Apenas dois deles o fizeram de forma parcial: Caseiros e Blumenau, que, apesar de considerarem como objetivo o controle de inundações, propõem apenas medidas estruturais.

\section{Política Municipal de Saneamento Básico}

Seis municípios aprovaram a política municipal de saneamento básico, ou os seus instrumentos, por lei: Alagoinhas, Belo Horizonte, Ouro Branco, São Paulo, Blumenau e Bombinhas. Também foram seis os que elaboraram a política municipal de saneamento básico e pretendem aprová-la por lei.

Foi observado que nenhum dos municípios atendeu a todo o conteúdo mínimo do plano. $\mathrm{O}$ atendimento a esse conteúdo mínimo foi verificado por meio de um checklist, no qual foram considerados todos os aspectos relacionados ao plano existentes na Lei do Saneamento e em seu Decreto de Regulamentação.

O artigo 19 da Lei do Saneamento estabelece o conteúdo mínimo a ser abrangido pelo plano e teve seu conteúdo inserido no checklist: plano elaborado pelo titular; áreas urbanas e rurais; diagnóstico do AA, ES, MRS e MAP; impactos nas condições de vida; indicadores sanitários, epidemiológicos, ambientais, hidrológicos e socioeconômicos; causas das deficiências detectadas; compatibilidade com os planos das bacias; objetivos e metas de curto, médio e longo prazos para o AA, ES, MRS e MAP; definição de programas, projetos e ações articulados com os objetivos e metas, compatíveis com o Plano Plurianual (PPA) e outros programas, com previsão das possíveis fontes de financiamento; ações para emergências e contingências; compatibilização entre os planos setoriais; mecanismos e procedimentos para a avaliação; indicadores para avaliar a eficiência e a eficácia; ampla divulgação do plano e dos estudos que o fundamentam; realização de audiências ou consultas públicas com recebimento de sugestões e críticas; revisões previstas a cada quatro anos, anteriormente ao PPA (BRASIL, 2007).

Além do disposto no artigo 19, merecem destaque outros dispositivos da Lei e de seu Decreto de Regulamentação, que também foram incorporados a esse checklist:

1. identificação dos usuários de baixa renda e apontamento de solução para o acesso aos serviços;

2. ampla participação da população e das associações e entidades representativas dos segmentos da sociedade;

3. divulgação dos estudos e do plano de forma integral, inclusive na Internet; e

4. participação de instância colegiada na avaliação do plano (BRASIL, 2007; 2014).

Os três primeiros itens estão assegurados pelo Decreto de Regulamentação da Lei do Saneamento, e o último pelo artigo $2^{\circ}$ da 
Lei do Saneamento, que garante a participação nos processos de formulação, planejamento e avaliação relacionados aos serviços públicos, ao apresentar definição para o controle social.

Com relação aos prestadores de serviços, todos os municípios apresentam clara definição no plano. Já com relação à regulação, para quatro municípios não foram encontrados registros sobre como serão regulados os serviços: Senador Canedo, Tangará da Serra, Buritis e Toledo, e um plano avaliou várias possibilidades, mas não apontou qual seria a melhor alternativa: Parnamirim. Os demais já fizeram uma opção por qual será a solução adotada para a regulação. Nenhum dos municípios abordou as condições para garantia à saúde e ao volume mínimo per capita, apenas dois deles definiram os direitos e deveres dos usuários, e nenhum deles definiu as condições para intervenção e retomada dos serviços. Dois não definiram uma instância responsável pelo controle social, seja mediante conferências e conselhos municipais ou por meio de câmaras ou comitês técnicos: Senador Canedo e Buritis. O município de São Paulo criou um Conselho Gestor do Fundo Municipal de Saneamento Ambiental, mas que se restringe às discussões sobre a destinação dos recursos do fundo. Com relação ao fundo de universalização, 11 municípios instituíram ou pretendem instituí-lo.

\section{Capacidade de gestão}

Para avaliar a capacidade de gestão dos municípios, foram observados alguns instrumentos que podem contribuir para o seu fortalecimento. Inicialmente, foi investigado se os processos de planejamento adotaram algumas das metodologias formuladas com o foco no setor público, e foi constatado que sete planos adotaram algumas ferramentas, entretanto de forma descoordenada, sem optarem claramente por métodos disponíveis e seus princípios, mas já utilizando mecanismos que conferem caráter mais estratégico ao plano. Esses também foram os planos que se demonstraram mais participativos: Alagoinhas, Morada Nova, Parnamirim, Ariquemes, Boa Vista, Ouro Branco e Bombinhas. Todos esses realizaram atividades de participação social as quais podem ser comparadas aos brainstormings (ferramenta utilizada para a construção de cenários), grupos focais (ou consulta a especialistas) e também possibilitaram a incorporação da visão de diversos atores ao processo (princípio do PES). Com exceção dos planos de Boa Vista, coordenado pelo governo estadual de Buritis e Toledo, elaborados pelos prestadores, os outros 15 contemplaram o princípio do PES de que "quem planeja é quem governa”, já que esses foram elaborados pelos titulares. $\mathrm{O}$ plano de Boa Vista adotou a ferramenta SWOT (do inglês: forças, fraquezas, oportunidades e ameaças), utilizada para a construção de cenários, mas não considerou todas as diretrizes que a denomina. Foram realizadas reuniões para levantamento de pontos fortes e pontos fracos, mas não se elaborou a matriz característica do método, incluindo as oportunidades e ameaças, o que seria necessário para possibilitar a priorização por meio desse método.

A existência de dados no Sistema Nacional de Informações sobre Saneamento (SNIS) e a coordenação do processo de elaboração do plano foram os aspectos que mais se destacaram positivamente, apesar de dois municípios não conterem nenhum dado no SNIS, Senador Canedo e Blumenau, e de quatro apresentarem dados para um ou dois dos três componentes (água, esgoto e resíduos): Tangará da Serra, Alagoinhas, Morada Nova e Toledo. Algumas questões, apesar de terem sido tratadas por alguns planos, ainda necessitariam de aprimoramento pela maioria: análise política e institucional, definição de mecanismos, procedimentos de avaliação e de indicadores de eficiência e eficácia. Os municípios que ainda não regularizaram suas situações com os prestadores mencionaram que estão providenciando a renovação ou a assinatura do contrato. Como os planos não atenderam ao conteúdo mínimo estabelecido pela Lei, os respectivos contratos de prestação dos serviços podem ser questionados, já que o plano é uma das exigências para garantir a sua validade.

\section{Sustentabilidade}

Para avaliar a sustentabilidade social e de governança da política e do plano, foi analisado, principalmente, o processo participativo. A partir da análise de conteúdo, avaliou-se a divulgação do plano, de seus estudos e das atividades de participação; a participação das associações e entidades representativas dos segmentos da sociedade; a abrangência territorial das atividades de participação, inclusive das áreas rurais; a realização de audiências públicas e de consultas públicas com recebimento de sugestões e críticas; e a aprovação por instâncias colegiadas como os conselhos. A partir dessas informações, os processos participativos foram classificados com base na descrição dos níveis de participação cidadã, propostos por Bernardes et al. (2011), que vão de 0 , quando "a comunidade não participa" do processo, até 6, quando "a comunidade controla o processo". Os municípios que tiveram processos sem participação foram os de Senador Canedo e Tangará da Serra. Sete municípios foram classificados no nível 1, em que "a comunidade é informada e espera-se a sua conformidade": Salvador, Serra, Belo Horizonte, Buritis, São Paulo, Toledo e Blumenau. Os municípios do Rio de Janeiro e de Caseiros tiveram os seus processos classificados no nível 2, no qual a "administração busca apoios que facilitem sua aceitação e o cumprimento das formalidades que permitam a sua aprovação". Os planos de Parnamirim, Boa Vista e Bombinhas ficaram no nível 3, em que "a administração convida a comunidade a contribuir no diagnóstico e para conhecer o plano já elaborado, esperando modificá-lo só no estritamente necessário". Os planos mais participativos foram os de Alagoinhas, Morada Nova, Ariquemes e Ouro Branco, classificados no nível 4, no qual “a administração convida a comunidade a contribuir no diagnóstico e também para conhecer uma versão preliminar do plano, a ser modificada, esperando que o seja em certa medida”. A maioria dos municípios definiu como se dará a participação social na implementação do plano, com exceção de seis: Senador Canedo, Tangará da Serra, Serra, Buritis, São Paulo e Toledo. A maioria dos planos também foi aprovada por algum instrumento legal, sendo oito 
por lei: Alagoinhas, Salvador, Morada Nova, Parnamirim, Ariquemes, Boa Vista, Serra e Ouro Branco; cinco por decreto: Belo Horizonte, Rio de Janeiro, Caseiros, Blumenau e Bombinhas; e para os outros cinco não foram encontrados registros de aprovação.

\section{CONSIDERAÇÕES FINAIS}

Alguns dos planos avaliados destacaram-se por terem atendido de forma geral à maioria das categorias: Alagoinhas, Morada Nova, Ariquemes e Ouro Branco. Também foram esses os que tiveram os processos mais participativos e que adotaram algumas técnicas de planejamento. Tal constatação leva a reforçar a hipótese de que quanto mais participativo o processo mais informações se agregam ao plano, possibilitando a incorporação das demandas, e maior a possibilidade de ser implementado e interferir na qualidade do saneamento do município. Esses quatro planos foram elaborados para os quatro componentes do saneamento e também foram aprovados por lei. Os municípios apresentam população entre 35 e 140 mil habitantes. Dois foram elaborados com apoio de universidades e dois com recursos da FUNASA, e os custos variaram de R $\$ 126$ mil a cerca de R \$ 250 mil. Servidores de Ouro Branco participaram de oficina do MCIDADES na qual receberam orientações sobre o PMSB e, a partir daí, iniciaram a elaboração, o que demonstra a importância de processos de capacitação dos atores envolvidos com o planejamento municipal. Desses quatro planos, dois são da região Nordeste e os outros dois da Norte e Sudeste.

Outros quatro planos se destacaram como os que atenderam ao menor número de categorias: Senador Canedo, Tangará da Serra, Buritis e Toledo. Não adotaram métodos de planejamento e também não realizaram processos efetivamente participativos. Destes, um foi elaborado por uma construtora, e dois a partir de um "modelo" disponibilizado por suas companhias estaduais, gerando dúvidas sobre a capacidade de construtoras e prestadores de serviços captarem adequadamente as necessidades do município, como também sobre eventual conflito de interesses entre usuários dos serviços, municípios, prestadores e empreiteiras. Esses quatro planos, de municípios em que a população varia de 23 a 120 mil habitantes, foram elaborados somente para o AA e o ES. Dois deles são da região Centro Oeste, um da Sudeste e o outro da Sul.

Os cinco planos oriundos de capitais dos estados - Belo Horizonte, Boa Vista, Rio de Janeiro, Salvador e São Paulo - são supostamente os que teriam mais recursos disponíveis para elaborarem bons planos; entretanto, analisando os resultados, pode-se questionar se os recursos tecnológicos, humanos e financeiros não estão disponíveis ou não são suficientes, ou se não houve prioridade política para se aglutinarem esforços em torno desse processo.

De uma forma geral, todos os municípios estão diante de grandes desafios para aprimorar as suas políticas e os seus planos de saneamento básico, a serem superados nos processos de avaliação e revisão. A superação desses desafios é necessária para se alcançar a melhoria das condições sanitárias e ambientais dos municípios, e para promover a melhoria da qualidade de vida da população. Defende-se que os municípios devam aspirar à formulação de políticas e planos que possam de fato contribuir para se atingir melhores níveis de acesso aos serviços públicos e às soluções adequadas, mas também para se alcançar melhor qualidade deles. O monitoramento e a avaliação dos planos poderão mostrar o que necessitará ser aprimorado.

As metodologias utilizadas para planejar podem determinar a sustentabilidade do plano e, portanto, a viabilidade de sua posterior implementação. A partir do exame das diversas escolas de planejamento, é possível compreender que algumas delas são mais apropriadas para a utilização pelo setor público. Para cada realidade, podem ser selecionados métodos mais adequados. Como o Plansab se constitui em um grande esforço de planejamento do setor, é pertinente a adoção de métodos similares, devidamente adaptados às realidades municipais, considerando a visão de diversos atores, selecionando condicionantes, hipóteses e cenários, além de se preverem metas, estratégias, macrodiretrizes, programas e mecanismos de monitoramento.

Diante de todos os resultados, discussões e considerações, pode-se afirmar que os processos que adotaram métodos de planejamento e de participação social chegaram a resultados mais satisfatórios, e apresentam maiores chances de interferir na qualidade e na organização do saneamento básico, bem como resultar em melhorias da qualidade de vida da população.

É recomendável que os municípios avaliem e monitorem sistematicamente os planos, com o intuito de aprimorá-los e incorporar elementos que não tenham sido considerados em um momento inicial, observando-se os princípios da universalidade, equidade, integralidade, intersetorialidade, uso de tecnologia apropriada, respeito às peculiaridades locais, qualidade e regularidade. Recomenda-se também que busquem adotar métodos e metodologias de planejamento e de participação social, observando as formulações e avaliações realizadas nesse trabalho e em outros similares.

Para os municípios que ainda não elaboraram seus planos, é recomendável observarem as dificuldades e os problemas enfrentados pelos que já o fizeram, para que possam trilhar caminhos diferentes, superando desafios e dificuldades já detectados, e apontados nessa pesquisa. Observar os princípios e os elementos avaliados nesse artigo poderá subsidiar os atores envolvidos no planejamento a tornar o conteúdo do plano mais abrangente e a atender ao disposto na legislação.

Aos governos estaduais, recomenda-se que busquem estratégias e mecanismos para apoiarem os municípios na superação dos desafios apontados, mas de forma que não comprometam a autonomia e a coordenação atribuída a esses pela Lei do Saneamento. Também seria interessante que os estados incentivassem os municípios a aprimorarem a qualidade dos planos, lançando ações específicas para isso, de assistência técnica e/ ou capacitação, e sugerindo melhorias quando for disponibilizar recursos financeiros para a área de saneamento.

Ao governo federal, é necessário sugerir que fortaleça os seus mecanismos de apoio, tanto técnicos como financeiros, à elaboração de planos. Foi constatado que os planos elaborados com o apoio da FUNASA são 
mais abrangentes, tanto em relação ao seu conteúdo como à consideração de visões dos diversos atores sociais; que as oficinas, e publicações do MCIDADES podem contribuir para a elaboração de planos com caráter participativo e intersetorial, e que contemplem princípios como a universalização, a equidade e a integralidade. Portanto, há que se considerar a necessidade de ampliar ações de apoio, assistência técnica, capacitação, entre outras daquelas consideradas como medidas estruturantes pelo Plansab, para que o governo federal possa contribuir com a melhoria do planejamento e da gestão municipal. Também seria pertinente que o governo federal avaliasse o conteúdo mínimo que os planos deveriam conter para atender à legislação vigente, para que, quando for liberar recursos financeiros para os municípios, possa fomentar o aprimoramento dos planos.

Para novas pesquisas, considera-se pertinente o aprofundamento sobre o uso de metodologias de planejamento para elaborar os planos municipais de saneamento básico e sobre os processos de participação social, bem como a realização de avaliações sobre a incorporação dos princípios da política pública de saneamento.

\section{REFERÊNCIAS}

ALAGOINHAS. (2004) Plano municipal de saneamento ambiental de Alagoinhas. Salvador: Prefeitura Municipal de Alagoinhas; UFBA.

ARIQUEMES. (2010) Plano de saneamento básico de Ariquemes/RO. Ariquemes: Prefeitura Municipal de Ariquemes; Fundação Nacional de Saúde. Disponível em: <http://www.ariquemes.ro.gov.br/default. asp? secao=secretarias.asp\&idsec $=20 \&$ subsec $=469 \&$ tit $=$ Plano $\% 20$ Municipal\%20de\%20Saneamento\%20-\%20Continua\%E7\%E3o>. Acesso em: 26 nov. 2010

AZEVEDO, C.S. (1992) Planejamento e gerência no enfoque estratégico situacional de Carlos Matus. Cadernos de Saúde Pública. Rio de Janeiro, v. 8, n. 2, p. 129-133

BERNARDES, R.S.; SCÁRDUA, M.P.; CAMPANA, N.A. (org.) (2011) Guia para elaboração de planos municipais de saneamento. 2 ed. Brasília: Ministério das Cidades, 152 p.

BELO HORIZONTE. (2010) Plano municipal de saneamento de Belo Horizonte 2008/2011. Atualização 2010. Belo Horizonte: Prefeitura de Belo Horizonte. Disponível em: <http://www.pbh.gov.br/comunicacao/pdfs/ politicaurbana/plano_municipal_saneamento/>. Acesso em: 6 mar. 2012.

BLUMENAU. (2008) Lei complementar $n^{\circ}$ 696, de 10 de dezembro de 2008. Blumenau. Disponível em: <http://www.jusbrasil.com. br/legislacao/974825/lei-complementar-696-08-blumenau-0>. Acesso em: 13 mar. 2012.

BLUMENAU. (2009) Plano municipal de saneamento. Abastecimento de água, esgotamento sanitário, manejo de resíduos sólidos e limpeza urbana, manejo e drenagem das águas pluviais, controle de vetores. Blumenau. Disponível em: <www.samae.com.br/arquivos/plano_ municipal_saneamento.pdf>. Acesso em: 5 dez. 2010.

BOA VISTA. (2011) Plano diretor de saneamento integrado da cidade de Boa Vista/RR. Boa Vista: Governo do Estado de Roraima; Secretaria de Estado de Infraestrutura - SEINF; Prefeitura Municipal de Boa Vista.

BOMBINHAS. (2009) Lei $n^{\circ}$ 1.131, de 26 de agosto de 2009. Estabelece a política municipal de saneamento básico e dá outras providências. Disponível em: <http://www.jusbrasil.com.br/legislacao/936695/lei-113109-bombinhas-0>. Acesso em: 5 mar. 2012.
BOMBINHAS. (2010a) Plano municipal de saneamento básico de Bombinhas. Bombinhas: Prefeitura Municipal de Bombinhas. Disponível em: <http://antigo.bombinhas.sc.gov.br/download/Ultima\%2Oversao\%20 do\%2OPlano\%20Municipal\%20de\%20Saneamento\%20Basico.pdf>. Acesso em: 28 mai. 2011.

BOMBINHAS. (2010b) Plano de mobilização social para elaboração do PMSB. Bombinhas: Prefeitura Municipal de Bombinhas. Disponíve em: <http://antigo.bombinhas.sc.gov.br/download/Plano\%20de\%20 Mobilizacao\%20Social\%20do\%2OPMSB\%20de\%20Bombinhas.pdf> Acesso em: 5 mar. 2012

BORJA, P.C. (2011) Elaboração de diagnóstico da situação de saneamento básico de um município: algumas recomendações: peça técnica $n^{\circ}$ 2. In: BORJA, P.C. Peças técnicas relativas a planos municipais de saneamento básico. Brasília: Ministério das Cidades, p. 87-115.

BRASIL. (2007) Lei no 11.445, de 5 de janeiro de 2007. Lei do Saneamento. Estabelece diretrizes nacionais para o saneamento básico; altera as Leis $n^{\circ}$ 6.766, de 19 de dezembro de 1979, 8.036, de 11 de maio de 1990, 8.666, de 21 de junho de 1993, 8.987, de 13 de fevereiro de 1995; revoga a Lei n 6.528, de 11 de maio de 1978; e dá outras providências. Disponível em: <http://www.planalto.gov.br/ ccivil_03/_ato2007-2010/2007/lei/111445.htm>. Acesso em: 27 out. 2011.

BRASIL. (2010a) Decreto no 7.217, de 21 de junho de 2010. Regulamenta a Lei $n^{\circ} 11.445$, de 5 de janeiro de 2007, que estabelece diretrizes nacionais para o saneamento básico, e dá outras providências. Disponível em: <http://www.planalto.gov.br/ccivil_03/ ato2007-2010/2010/Decreto/D7217.htm>. Acesso em: 27 out. 2011.

BRASIL. (2010b) Lei $n^{\circ}$ 12.305, de 2 de agosto de 2010. Institui a Política Nacional de Resíduos Sólidos; altera a Lei no 9.605, de 12 de fevereiro de 1998; e dá outras providências. Disponível em: <http:// www.planalto.gov.br/ccivil_03/_ato2007-2010/2010/lei/112305.htm> Acesso em: 13 set. 2014

BRASIL. (2014) Plano nacional de saneamento básico. Brasília: Ministério das Cidades, 220 p. Disponível em: <http://www.cidades.gov.br/images/ stories/ArquivosSNSA/PlanSaB/plansab_texto_editado_para_download pdf>. Acesso em: 15 set. 2014. 
BUARQUE, S.C. (2003) Metodologia e técnicas de construção de cenários globais e regionais. Texto para discussão n 939. Brasília. IPEA.

BURITIS. (2009) Plano municipal de saneamento. Disponível em: <http:// www.buritis.mg.gov.br/gabinete/plano_municipal_de_saneamento_de_ buritis.pdf>. Acesso em: 5 dez. 2010.

BURITIS. (2010) Decreto $n^{\circ} 274$, de 19 de março de 2010. Estabelece o regulamento para a realização da Consulta Pública prevista nos artigos 11, IV, 19, §50 e 51da Lei Federal no 11.445/2007. Disponível em: <www. buritis.mg.gov.br/gabinete/decreto_274.pdf>. Acesso em 4 mar. 12.

CASEIROS. (2011) Decreto $n^{\circ}$ 582, de 22 de junho de 2011. Aprova o plano municipal de saneamento básico do município de Caseiros e dá outras providências. Disponível em: http://portal.cnm.org.br/sites/7300/7325/ PMSB-planomunicipaldesaneamentobasico.pdf. Acesso em: 13 mar. 12.

CONSELHO MUNICIPAL DE MEIO AMBIENTE DA CIDADE DO RIO DE JANEIRO - CONSEMAC. (2012) Atas de reuniões. Disponível em: <http:// wwwO.rio.rj.gov.br/smac/consemac/index.shtm>. Acesso em: 20 mar. 2012.

GODET, M. (2011) Creating futures scenario planning as a strategic management tool. 2 ed. Paris. Economica Ltd., 369p.

HUERTAS, F. (1996) O método PES: entrevista com Matus. Trad. Giselda Barroso Sauveur. São Paulo: FUNDAP, 139 p.

IBGE-Instituto Brasileiro de Geografiae Estatística.(2010) Censo demográfico. Disponível em: <http://www.bge.gov.br/>. Acesso em: 12/03/2012.

MATUS, C. (1984) Planificación, liberdad y conflito. In: Argentina. Evaluación y uso de la información: manual de estrategias para el uso e incorporación de la información de evaluación. Buenos Aires, p.198-225.

MATUS, C. (1989) Adeus, Senhor Presidente. Trad. de Francisco A. Carneiro da Cunha Filho. Recife: Litteris Editora Ltda.,204 p.

MATUS, C. (2006) O plano como aposta. In: Giacomoni, J.; Pagnussat, J.L. (org.). Planejamento e orçamento governamental. Brasília: Coletânea. ENAP.

MATUS, C. (2007) Los trescinturones del gobierno. San Justo: Univ. Nacional de La Matanza, p.1-55.

MORADA NOVA. (2008) Plano de saneamento básico de Morada Noval CE. Morada Nova: Prefeitura Municipal de Morada Nova; Fundação Nacional de Saúde.

OURO BRANCO. (2011a) Plano municipal de saneamento ambiental de Ouro Branco - MG. Ouro Branco: Prefeitura Municipal de Ouro Branco; Fundação de Apoio à Universidade Federal de Viçosa. Disponível em: <http://www.sanusplan.com.br/ourobrancomg/>. Acesso em: O1 mar. 2012.

OURO BRANCO. (2011b) Lei $n^{\circ}$ 1.887, de 22 de dezembro de 2011. Dispõe sobre a política municipal de saneamento ambiental de Ouro Branco (MG), seus instrumentos e dá outras providências.

PAIM, J.S. (2O11) Universalidade, integralidade e equidade: caderno temático n० 1. In: Rezende, S.C. (org.). Cadernos temáticos. In: HELLER, L.; MORAES, L.R.S.; BRITTO, A. L.; BORJA, P.C.; REZENDE, S.C. Panorama do Saneamento Básico no Brasil. Brasília. Ministério das Cidades, v. 7. No prelo. Disponível em: <http://www.cidades.gov.br/plansab> Acesso em: O1 out. de 2011.
PARNAMIRIM. (2011) Plano municipal de saneamento ambiental do município de Parnamirim/RN. Parnamirim. Disponível em: <http://www. parnamirim.rn.gov.br/servicos>. Acesso em: 28 mai. 2011.

PEREIRA, T.S.T. (2012) Conteúdo e metodologia dos planos municipais de saneamento básico: um olhar para 18 casos no Brasil. Monografia (Especialização em Gestão e Tecnologia do Saneamento). Curso da Escola Nacional de Saúde Pública, Fundação Oswaldo Cruz, Brasília. 209 f.

RIO DE JANEIRO. (2011) Plano de Saneamento Básico do Município do Rio de Janeiro/RJ. Rio de Janeiro. Disponível em: <http://www.rio.rj.gov.br/ web/guest/exibeconteudo?article-id=2029432>. Acesso em: 1 mar. 2012.

RIVERA, F.U. (1992) Planejamento e programação em saúde: um enfoque estratégico. São Paulo. Abrasco, 222 p.

SALVADOR. (2010) Plano municipal de saneamento básico. Salvador: Secretaria Municipal dos Transportes Urbanos e Infraestrutura - SETIN Disponível em: <http://www.infraestrutura.salvador.ba.gov.br/index. php?option=com_wrapper\&ltemid=39>. Acesso em: 11dez. 11 .

SÃO PAULO. (2010) Plano municipal de saneamento básico de São Paulo. Disponível em: <www.prefeitura.sp.gov.br/habitacao>. Acesso em: 6 mar.2012.

SENADOR CANEDO. (2007) Plano municipal de saneamento básico. Senador Canedo: Serviço público de abastecimento de água e esgotamento sanitário; Instituto UNIEMP. Disponível em: <http://www. senadorcanedo.go.gov.br/sms.pdf>. Acesso em 21 jun. 2009

SERRA. (2012) Plano municipal de saneamento básico. Eixo: água e esgoto. Serra: Prefeitura Municipal da Serra. Disponível em $<$ http://www.serra.es.gov.br/portal_pms/ecp/noticia.do?evento=portlet\& pAc=not\&idConteudo=26664\&acao=proc\&pldPIc=\&app=\&app=site> Acesso em: 1 mar. 2012.

SILVA, F.J.A. (2012) A natureza dos planos municipais de saneamento é influenciada pelas instituições elaboradoras? Um estudo comparativo em três municípios de Minas Gerais. (Dissertação) - Escola de Engenharia, Universidade Federal de Minas Gerais, $139 \mathrm{f}$.

SILVEIRA, R.B. (2012) Princípios no planejamento em saneamento básico: estudo comparativo de três experiências brasileiras. (Dissertação) Escola de Engenharia da Universidade Federal de Minas Gerais, 188 f.

SILVEIRA, R.B.; HELER, L.; REZENDE, S. (2013a) Identificando correntes teóricas de planejamento: uma avaliação do Plano Nacional de Saneamento Básico (Plansab). Revista de Administração Pública, Rio de Janeiro, v. 47, n. 3, p. 601-622.

SILVEIRA, R.B:; HELER, L.; LISBOA, S.S. (2013b) Plano de saneamento ambiental de Penápolis, Brasil: uma avaliação à luz das teorias de planejamento. Revista AIDIS de Ingeniería y Ciencias Ambientalis, v. 6, n. 1, p. $32-48$.

TANGARA DA SERRA. (2006) Lei $n^{\circ} 2.557$, de 27 de junho de 2006 Dispõe sobre a criação do conselho municipal de saneamento ambiental, e dá outras providências.

TANGARA DA SERRA. (2009) Plano municipal de saneamento. Tangará da Serra: SAMAE.

TOLEDO. (2010) Plano Municipal de Saneamento Básico. Município de Toledo/PR. 1a ed. Disponivel em: <http://www.toledo.pr.gov.br/?q=pagina/ plano-municipal-de-saneamento-basico>. Acesso em: 10 jul. 2011. 